\title{
Research Letter \\ Effect of Compatibilizers on the Morphological Properties of ABS and LCP Blends
}

\author{
T. Das, ${ }^{1}$ K. Pal, ${ }^{2}$ B. Adhikari, ${ }^{1}$ and C. K. Das ${ }^{1}$ \\ ${ }^{1}$ Materials Science Centre, Indian Institute of Technology, Kharagpur 721302, India \\ ${ }^{2}$ Department of Mining Engineering, Indian Institute of Technology, Kharagpur 721302, India
}

Correspondence should be addressed to C. K. Das, chapal12@yahoo.co.in

Received 27 August 2007; Accepted 6 November 2007

Recommended by Dao Hua Zhang

The blends of acrylonitrile butadiene styrene (ABS) polymer and liquid crystalline polymer (LCP) were prepared using a meltblending technique in presence and absence of different types of nanosilica. The effect of $\mathrm{Zn}^{++}$coated nanosilica on thermal, dynamic mechanical, and morphological properties of ABS/LCP blends was studied. The $\mathrm{Zn}^{++}$coated nanosilica showed a significant effect on the above-mentioned properties of ABS/LCP blends by reacting at the interface between ABS and LCP. A substantial improvement in storage modulus of ABS/LCP blends was observed in presence of $\mathrm{Zn}^{++}$coated nanosilica. Epoxy encapsulated nanosilica was also used as a compatibilizer in this blend system. It is known that the epoxy end group reacts with the LCP reacting groups. But in this case, we cannot find desirable results, may be due to the presence of ABS as the matrix. So Zn-ion-coated nanosilica proved to be better than that epoxy encapsulated nanosilica for the ABS/LCP containing blends. The SEM morphology also corroborates the above-mentioned argument.

Copyright (C) 2007 T. Das et al. This is an open access article distributed under the Creative Commons Attribution License, which permits unrestricted use, distribution, and reproduction in any medium, provided the original work is properly cited.

\section{INTRODUCTION}

This paper deals with a polymer, which is in ideal material wherever superlative surface quality, colorfastness, and luster are required. ABS is a two-phase polymer blend. In recent years, numerous studies on blends of thermotropic liquid crystalline polymer (TLCP) and isotropic thermoplastic have been carried out due to the interest in the LCP fibril formation during processing and a significant enhancement in mechanical properties [1]. The presence of a high modulus and high strength TLCP as a dispersed phase in an engineering plastic can significantly alter the thermal properties of the blended material. Various types of liquid crystalline polymer blends have been reported and these include TLCP/polypropylene, TLCP/polycarbonate, and TLCP/poly (ethylene terephthalate) blends. ABS is an engineering plastic that finds extensive applications in the home and business appliances and automobile parts due to its cost effectiveness, good processability, and mechanical properties. Because of its good balance of properties, toughness, strength, and temperature resistance coupled with its ease of moulding and high quality surface finish, ABS has a very wide range of applications. These include domestic appliances, telephone handsets, computer, and other office equipment housings, lawn mower covers, safety helmets, luggage shells, pipes, and fittings. Because of the ability to tailor grades to the property requirements of the application and the availability of electroplatable grades, ABS is often found as an automotive interior and exterior trim component $[2,3]$.

Its drawbacks, such as low-heat-deflection temperature, prevent its further applications in structural parts or hightemperature applications. However, this causes the viscosity to significantly increase, which makes processing more difficult. Adding LCP to the matrix reduces the viscosity to some extent. Thus we can say that LCP acts as a nucleating agent in the system [4]. This paper aims to study the effects of compatibilizer additions on the mechanical strength and thermal stability behavior of injection molded ABS containing LCP. The compatibilizers used were solid epoxy resin and $\mathrm{Zn}^{++}$ coated nanosilica. Nanofillers have, for many years, had a high significance in the plastics industry. Nanofillers are basically understood to be additives in the solid form, which differ from the polymer matrix in terms of their composition and structure. They generally comprise inorganic materials, and more rarely organic materials. Inactive fillers or extenders raise the quantity and lower the prices, while active 
fillers bring about targeted improvements in certain mechanical or physical properties [5]. The activity of active fillers may have a variety of causes, such as the formation of a chemical bond (e.g., cross linking by carbon black in elastomers), filling of a certain volume, disruption of the conformational position of a polymer matrix, immobilization of adjacent molecule groups, and possible orientation of the polymer material [6].

\section{EXPERIMENTAL}

\subsection{Materials}

The acrylonitrile butadiene styrene polymer (ABS) had a melting temperature of $180^{\circ} \mathrm{C}$. Its specific gravity is 2.18 . The LCP used was a copolyester of hydroxybenzoic acid (HBA) and hydroxynapthoic acid (HNA) marketed by Ticona, KY, USA under the trade name Vectra A950. It had a melting temperature of $280^{\circ} \mathrm{C}$ and the glass transition temperature of $108^{\circ} \mathrm{C}$.

\subsection{Preparation of sample}

Blends were prepared by melt mixing at $250^{\circ} \mathrm{C}$ using a corotating twin-rotor high-temperature internal mixer with a rotor speed of $80 \mathrm{rpm}$. The residence time of polymer melt in the mixing chamber is the order of three to five minutes. ABS/LCP blends with different ratios and compatibilizers were prepared. The blends were molded at $230^{\circ} \mathrm{C}$ and a pressure of $20 \mathrm{MPa}$ in a compression molding press for five minutes.

\subsection{Wide angle $X$-ray diffraction measurements}

X-ray diffraction was performed with a PW 1840 X-ray diffractometer with a copper target $(\mathrm{Cu}-\mathrm{K} \alpha)$ at a scanning rate of $0.0502 \theta / \mathrm{s}$, chart speed $10 \mathrm{~mm} / 2 \theta$, range $5000 \mathrm{c} / \mathrm{s}$, and a slit of $0.2 \mathrm{~mm}$, applying $40 \mathrm{kV}, 20 \mathrm{~mA}$, to asses the change of crystallinity of the blends as a function of blend ratio (10).

\subsection{Dynamic mechanical analysis}

Dynamic mechanical properties of the blends were analysed using a TA instrument DMA 2980 model in bending single cantilever mode. The samples were subjected to a sinusoidal displacement of $0.1 \%$ strain at a frequency of $1 \mathrm{~Hz}$ from 25 to $250^{\circ} \mathrm{C}$ and a heating rate of $10^{\circ} \mathrm{C} \mathrm{min}^{-1}$. The storage modulus $\left(\mathrm{E}^{\prime}\right)$, loss modulus $\left(\mathrm{E}^{\prime \prime}\right)$, and loss tangent $(\tan \delta)$ were measured for each sample in this temperature range.

\subsection{Scanning electron microscopy}

Morphology of the blends was studied using a scanning electron microscope (SEM) (JSM-5800 of JEOL Co., Tokyo, Japan) after auto sputter coating of the sample surface with gold.
TABLE 1: Compound formulation.

\begin{tabular}{lcccc}
\hline Sample no. & ABS & LCP & $\begin{array}{c}\text { Epoxy } \\
\text { encapsulated } \\
\text { nanosilica }\end{array}$ & $\begin{array}{c}\mathrm{Zn}^{++} \text {coated } \\
\text { nanosilica }\end{array}$ \\
\hline 1 & 100 & - & - & - \\
2 & 60 & 40 & - & - \\
3 & 50 & 50 & - & - \\
4 & 50 & 50 & 5 & - \\
5 & 50 & 50 & - & 5 \\
\hline
\end{tabular}

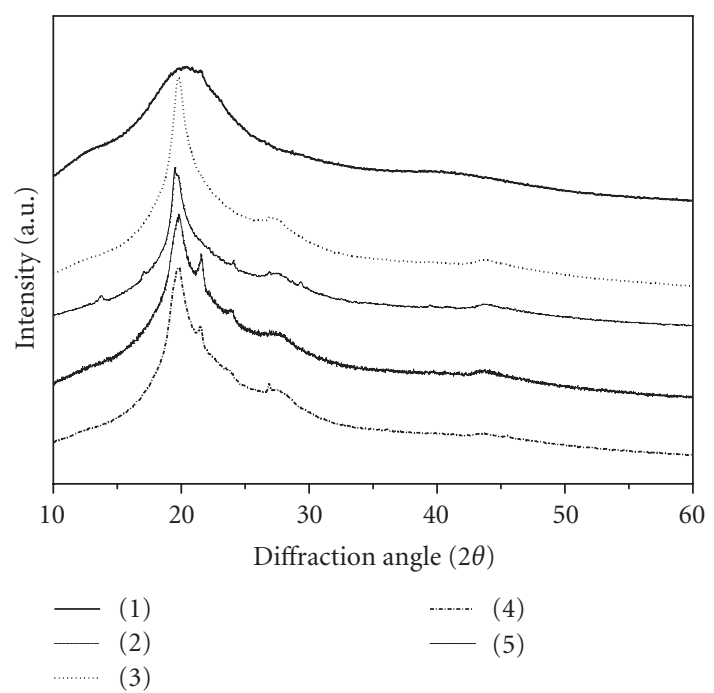

FIGURE 1: Wide-angle X-ray diffractograms of the ABS/LCP blend.

\section{RESULTS AND DISCUSSIONS}

\subsection{Compound formulations}

Compounding formulations based on changing of the ABS and LCP contents are shown in Table 1. For vulcanization, the compatibilizers such as Epoxy encapsulated nanosilica and $\mathrm{Zn}^{++}$coated Nanosilica are added.

\subsection{X-ray analysis}

The X-Ray analysis of the ABS and LCP blends are shown in Figure 1. The X-ray diffraction says that for pure ABS, the $2 \theta$ value is around $20^{\circ}$. But with addition of LCP in the matrix, the $2 \theta$ value slightly shifts to the lower side. The crystallinity falls with the addition of LCP and shown in Table 2. This decrease is due to the partial miscibility of the blend. The LCP fibers hinder the migration and diffusion of ABS molecules to the surface of the growing polymers crystal in the blend, resulting in a decrease in the percent crystallinity. With the addition of epoxy as a compatibilizer, the value again shifts to the lower side. But in case of sample 5 , it shows a broad peak. The $2 \theta$ value also increases. This increase is associated with the increase in the crystallize size, and indicates that the 
TABLe 2: Percentage crystallinity.

\begin{tabular}{cc}
\hline Sample no. & \% crystallinity \\
\hline 1 & 11 \\
2 & 8 \\
3 & 10 \\
4 & 9 \\
5 & 14 \\
\hline
\end{tabular}

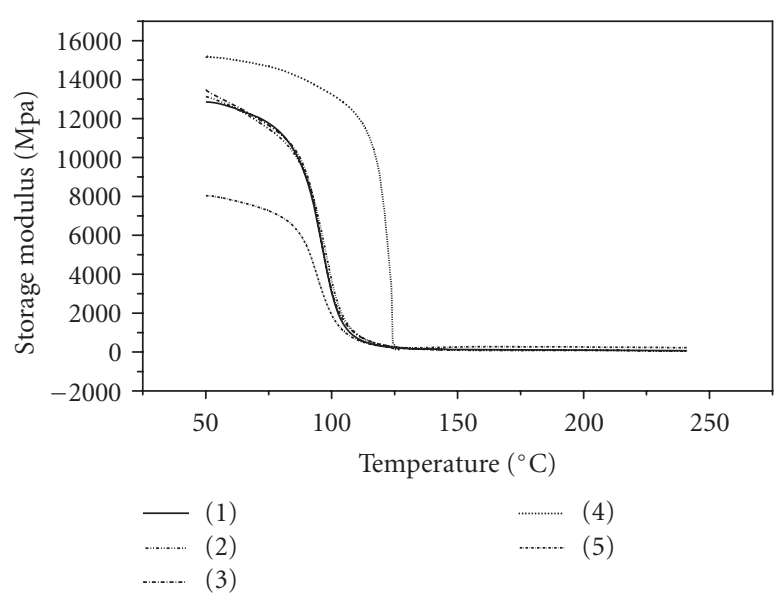

Figure 2: Storage modulus of ABS/LCP blend.

LCP acts as a nucleating agent for the above system in presence of $\mathrm{Zn}^{++}$coated Nanosilica [7].

This suggests that the reactivity of the $\mathrm{Zn}^{++}$coated nanosilica towards the LCP and ABS is more efficient. As it is known, the compatibilized blends crystallinity is always lower than those of the uncompatibilized blends due to the random structure of the formed graft block copolymers, which will modify the ordered structure of base polymers.

\subsection{DMTA analysis}

The storage modulus of the ABS/LCP with and without compatibilizers is shown in Figure 2. The storage modulus for the blend system says that the blend shows a higher-storage modulus than the pure one, that is, the pure ABS shows less storage modulus in respect to the other blends in the system. This improvement in $\mathrm{E}^{\prime}$ is due to a high intrinsic modulus of LCP phase, which consists of rigid rod-like molecules. This enhancement is predominant in presence of compatibilizers. However, the LCP shows a higher-storage modulus than all other systems due to the increase in stuffiness of the polymer.

The storage modulus of the blend decreases with the increase of temperature and the LCP content $[8,9]$. This may be due to the reinforcement imparted by LCP that permits stress transfer from the matrix to the filler. Sample 5 shows the highest-storage modulus value. So we could say that the sample containing $\mathrm{Zn}^{++}$coated nanosilica as a compatibilizer is more stable and have better properties in respect to all other blends in the system.

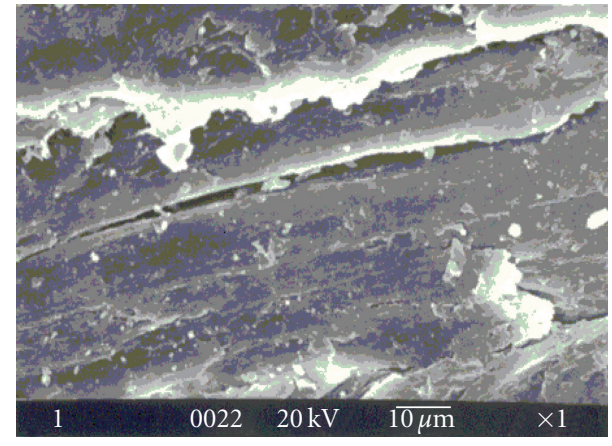

(a)

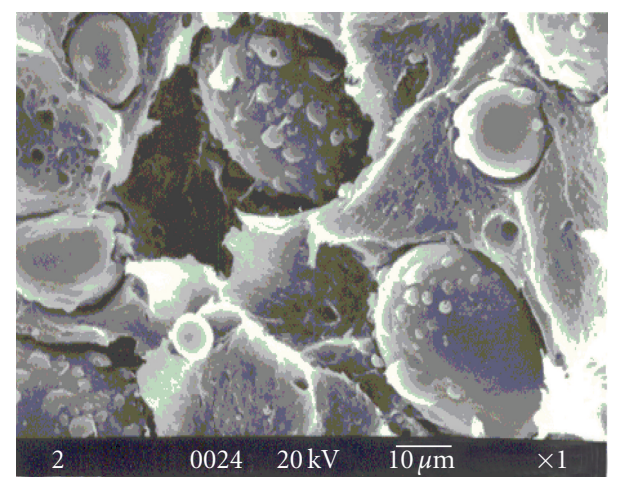

(b)

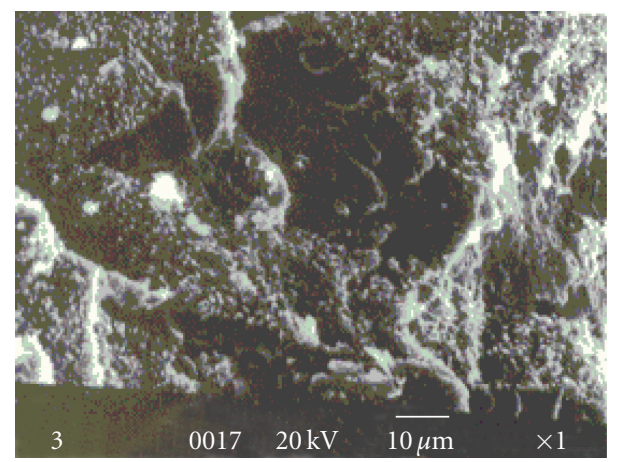

(c)

FIGURE 3: SEM micrograph of the blend system (a) ABS/LCP, (b) $\mathrm{ABS} / \mathrm{LCP} / \mathrm{Zn}^{++}$coated Nanosilica, and (c) ABS/LCP/Epoxy encapsulated nanosilica.

\subsection{SEM study}

The surface morphology of the ABS/LCP blend system in presence and absence of compatibilizers is shown in Figure 3. The fracture surface of the ABS/LCP blends is studied using a scanning electron microscope (SEM).The micrograph of a containing blend shows the fibril nature of the LCP domains in the predominant ABS matrix phase. These fibrils are very long and thin, which were dispersed homogeneously in the matrix phase. But in case of a sample containing ABS, $\mathrm{LCP}$, and $\mathrm{Zn}^{++}$coated nanosilica, it shows a clear and distinct phase of fibrillation indicating that in presence of $\mathrm{Zn}^{++}$ 
coated nanosilica, the blend shows the best thermal, dynamical, and crystalline character, whereas in case of other compatibilizers, the phase is not distinctly seen. That is, the compatibilizers are not finely dispersed in the matrix, indicating a poor adhesion between them.

\section{CONCLUSIONS}

From the result, it is observed that the reactivity of the $\mathrm{Zn}^{++}$ coated nanosilica towards the LCP and ABS is more efficient than epoxy encapsulated nanosilica, and a sample containing $\mathrm{Zn}^{++}$coated nanosilica as a compatibilizer is more stable and have better properties in respect to all other blends in the system.

It is seen that ABS and LCP with $\mathrm{Zn}^{++}$coated nanosilica showed a clear and distinct phase of fibrillation. It is also visible that in presence of $\mathrm{Zn}^{++}$coated nanosilica, the blend showed the best thermal, dynamical, and crystalline character, whereas in case of other compatibilizers, the phase is not distinctly seen.

So finally, we can conclude that blends of $\mathrm{Zn}^{++}$coated nanosilica with LCP and ABS are more efficient and dynamically stable than epoxy encapsulated nanosilica.

\section{REFERENCES}

[1] "Acrylonitrile butadiene styrene," from Wikipedia, the free encyclopedia.

[2] W. B. Xie, K. C. Tam, C. Y. Yue, Y. C. Lam, L. Li, and X. Hu, "Mechanical properties and morphology of LCP/ABS blends compatibilized with a styrene-maleic anhydride copolymer," Polymer International, vol. 52, no. 5, pp. 733-739, 2003.

[3] B. E. Tiganis, L. S. Burn, P. Davis, and A. J. Hill, "Thermal degradation of acrylonitrile-butadiene-styrene (ABS) blends," Polymer Degradation and Stability, vol. 76, no. 3, pp. 425-434, 2002.

[4] S. C. Tjong and W. Jiang, "Performance characteristics of compatibilized ternary Nylon 6/ABS/LCP in-situ composites," Journal of Materials Science, vol. 39, no. 8, pp. 2737-2746, 2004.

[5] K. I. Suresh, B. S. Sitaramam, and K. V. S. N. Raju, "Effect of copolymer composition on the dynamic mechanical and thermal behaviour of butyl acrylate-acrylonitrile copolymers," Macromolecular Materials and Engineering, vol. 288, no. 12, pp. 980-988, 2003.

[6] J. H. Hong, Y.-T. Sung, K. H. Song, et al., "Morphology and dynamic mechanical properties of poly(acrylonitrile- butadienestyrene)/polycarbonate/clay nanocomposites prepared by melt mixing," Composite Interfaces, vol. 14, no. 5-6, pp. 519-532, 2007.

[7] A. Misra, G. Sawhney, and R. A. Kumar, "Structure and properties of compatibilized blends of polyamide- 6 and ABS," Journal of Applied Polymer Science, vol. 50, no. 7, pp. 1179-1186, 1993.

[8] B. Majumdar, H. Keskkula, and D. R. Paul, "Morphology of nylon 6/ABS blends compatibilized by a styrene/maleic anhydride copolymer," Polymer, vol. 35, no. 15, pp. 3164-3172, 1994.

[9] T. Limtasiri and A. I. Isayev, "Blends of thermotropic polyester with poly(phenylene oxide)," Journal of Applied Polymer Science, vol. 42, no. 11, pp. 2923-2932, 1991. 

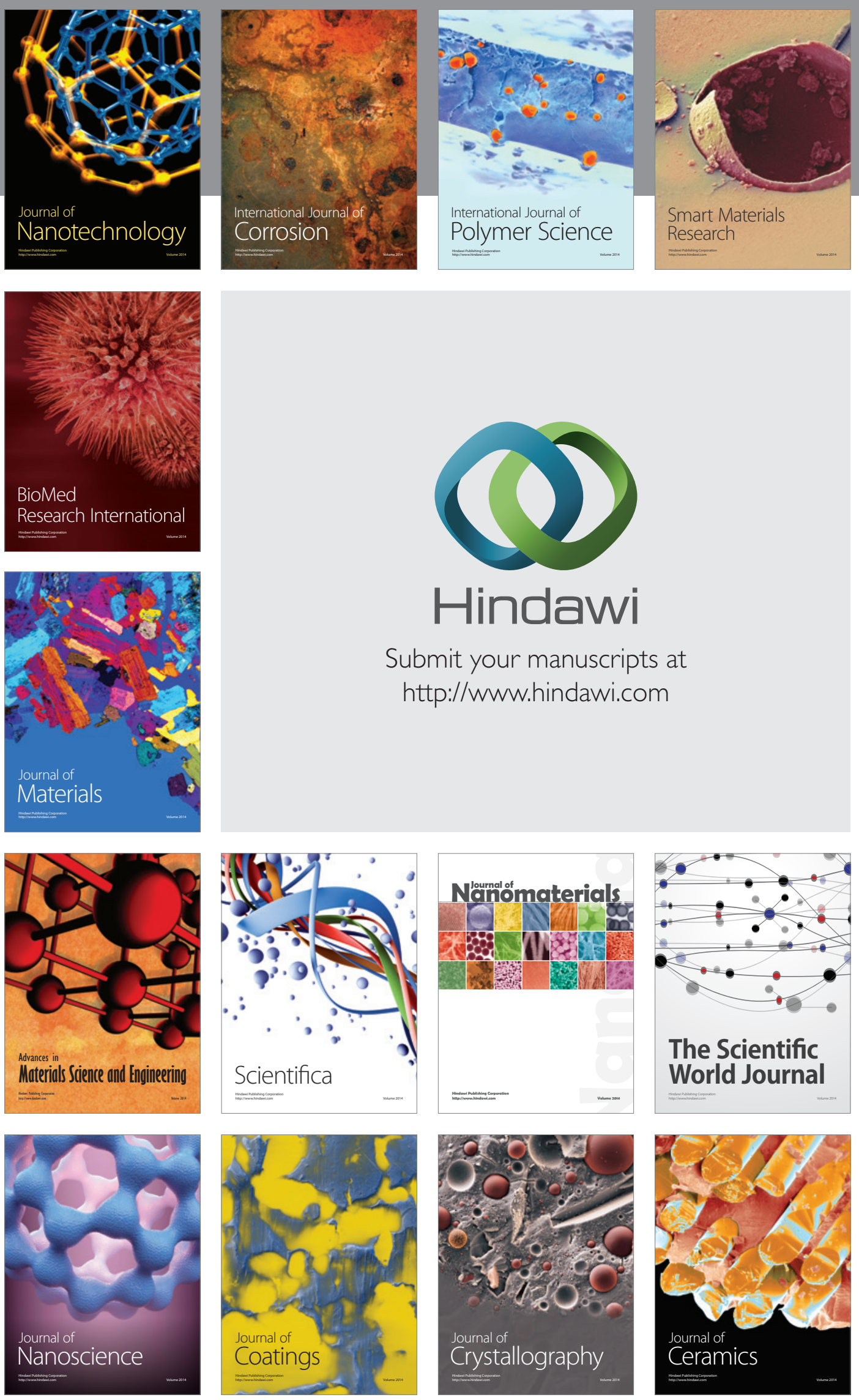

The Scientific World Journal

Submit your manuscripts at

http://www.hindawi.com

\section{World Journal}

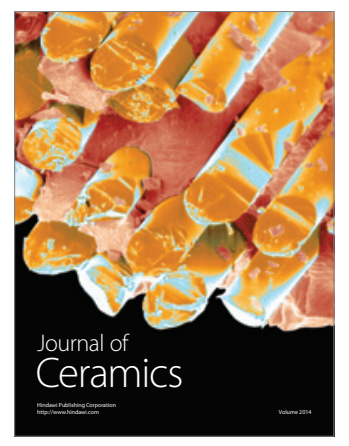

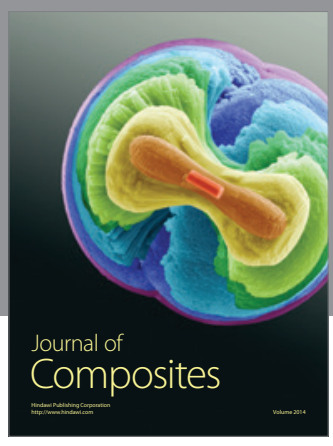
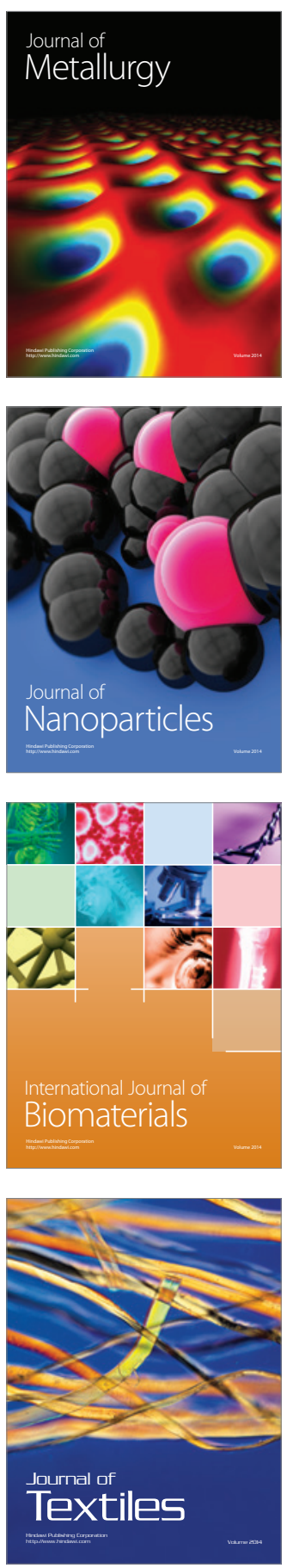